
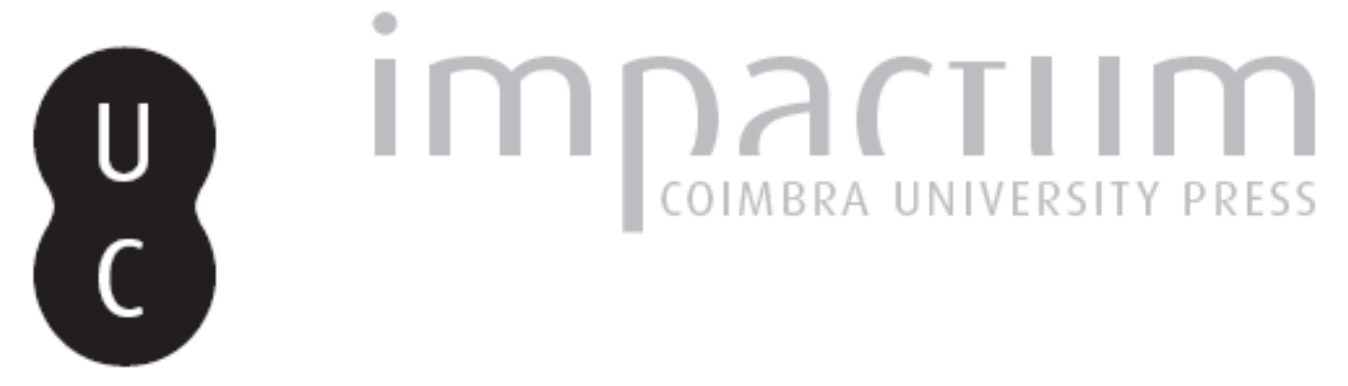

\title{
Análise espacial no Baixo sul da Bahia: uma modelagem sobre a extensão do sítio de Ituberá-BA
}

\author{
Autor(es): $\quad$ Silva, Luis Eduardo Cunha; Nolasco, Marjorie Csebrko
}

Publicado por: Imprensa da Universidade de Coimbra

URL persistente:

URI:http://hdl.handle.net/10316.2/36896

DOI:

DOI:http://dx.doi.org/10.14195/0871-1623_33_15

Accessed : $\quad$ 26-Apr-2023 09:29:10

A navegação consulta e descarregamento dos títulos inseridos nas Bibliotecas Digitais UC Digitalis, UC Pombalina e UC Impactum, pressupõem a aceitação plena e sem reservas dos Termos e Condições de Uso destas Bibliotecas Digitais, disponíveis em https://digitalis.uc.pt/pt-pt/termos.

Conforme exposto nos referidos Termos e Condições de Uso, o descarregamento de títulos de acesso restrito requer uma licença válida de autorização devendo o utilizador aceder ao(s) documento(s) a partir de um endereço de IP da instituição detentora da supramencionada licença.

Ao utilizador é apenas permitido o descarregamento para uso pessoal, pelo que o emprego do(s) título(s) descarregado(s) para outro fim, designadamente comercial, carece de autorização do respetivo autor ou editor da obra.

Na medida em que todas as obras da UC Digitalis se encontram protegidas pelo Código do Direito de Autor e Direitos Conexos e demais legislação aplicável, toda a cópia, parcial ou total, deste documento, nos casos em que é legalmente admitida, deverá conter ou fazer-se acompanhar por este aviso.

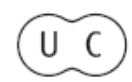




\section{Cadernos de Geografia}
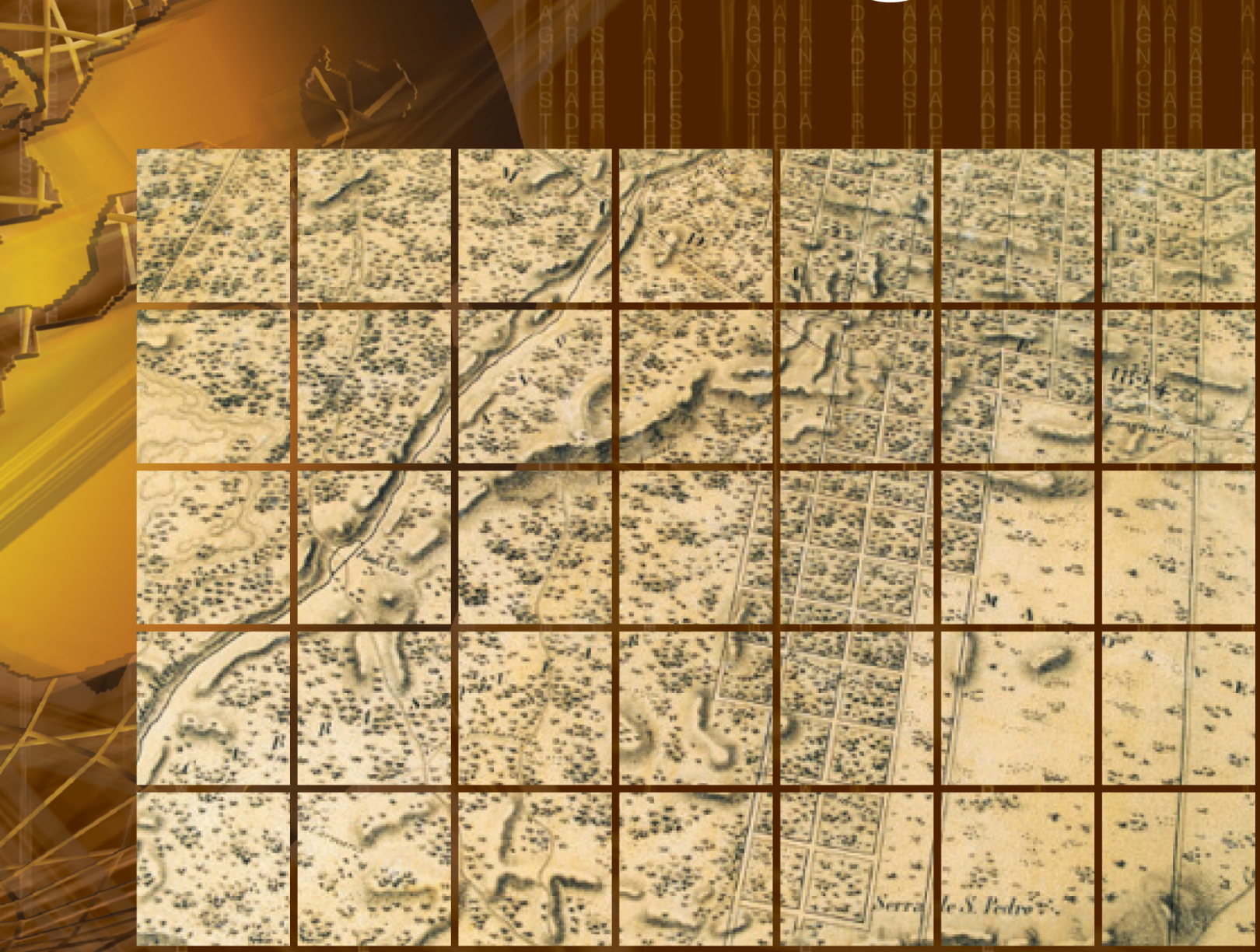

№ 33 - 2014

Imprensa da Universidade de Coimbra Faculdade de Letras | Universidade de Coimbra 


\section{Análise espacial no Baixo sul da Bahia: uma modelagem sobre a extensão do sítio de Ituberá-BA* Spatial analysis in the lower south of Bahia: Extended modelling of the Ituberá- BA site}

\section{Luis Eduardo Cunha Silva}

Bolsista PIBIC-FAPESB. Licenciando em Geografia. UEFS.

edugeo.cunha@gmail.com

\section{Marjorie Csebrko Nolasco}

Departamento de Ciências Exatas DEXA - UEFS.

mcn@uefs.br

Introdução

A área de Proteção Ambiental do Pratigi (APA do Pratigi), localiza-se na sub região do Baixo Sul do estado da Bahia-Brasil. Abrange os municípios de Ibirapitanga, Igrapiuina, Ituberá, Nilo Peçanha e Pirai do Norte, totalizando uma extensão territorial de $472.455 \mathrm{~km}^{2}$ (Figura 01), e foi escolhida como objeto de estudo para a presente pesquisa. . propriedades em função de alguns processos de reforma agrária.

Na APA, há núcleos de ocupação humana, representados por comunidades campesinas, sendo algumas de ocupação tradicional que desenvolvem atividades agrícolas e artesanais de extrativismo. Além disso, o baixo Sul da Bahia consolidou-se como uma região policultora de gêneros alimentícios,

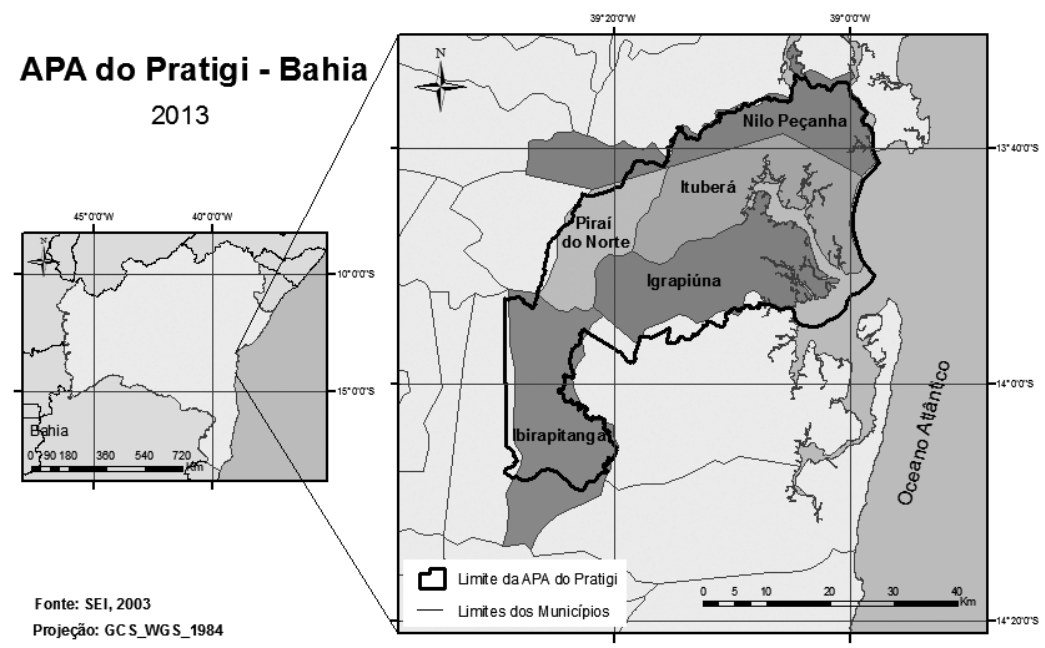

Figura 1

Localização da APA do Pratigi, mapa da Bahia a esquerda.

Elaboração: CUNHA, 2013.

A presente região de estudo, integra o processo de ciclos econômicos nacionais de exportação do cacau e da borracha, tendo parcela do seu território ocupado por estas culturas até a atualidade. Essa dinâmica produtiva influenciou também a estrutura fundiária local caracterizada até a década de 90 pela presença de grandes latifúndios, porém nos últimos anos encontram-se alterações nos últimos anos pela fragmentação das grandes chegando a ser conhecida como; região policultora do nordeste brasileiro. (Adan,2011).

No inicio do processo de colonização portuguesa, essa extensão do território nacional, passou por um intenso processo de povoamento e exploração dos recursos naturais. Durante séculos, o litoral brasileiro concentrou as atividades agropecuárias, tendo em vista a dificuldade dos colonizadores em ampliar as incursões pelo interior do país (TonHASCA Jr., 2005).

Este trabalho corresponde à comunicação, com o mesmo título, apresentada no VIII Colóquio de Geografia de Coimbra, subordinado ao tema “Espaço, Natureza e Sociedade. A Geografia na Estratégia 2020 da Região Centro”, realizado na Faculdade de Letras da Universidade de Coimbra, nos dias 27 e 28 de março de 2014. 
Trabalhando nesta perspectiva, a Historia Ambiental, compreende que todo o contexto histórico de uma região, ou nação, reflete na configuração da paisagem. Segundo dados e informações coletadas restam apenas $7,91 \%$ da Mata Atlântica original em todo o território brasileiro, incluindo os remanescentes florestais acima de 100 ha. Salientando que, considerados todos os fragmentos de floresta nativa acima de 3 ha, o numero não passa dos 11\%. (Fundação SOS Mata Atlântica,2012). Desta forma pretendeu-se analisar no presente trabalho, mapas e cartogramas históricos que representassem as atividades e configurações presentes em determinados períodos da colonização portuguesa.

\section{Metodologia}

A primeira etapa da pesquisa consisti numa revisão de literatura referente á Historia Ambiental e cartografia Histórica da região, buscando explanar adquirir conceitos relacionados ao tema e a inserção dos conhecimentos geográficos nesta abordagem.

Realizou-se também um levantamento cartográfico com a busca de dados históricos que representassem a espacialização das atividades produtivas, bem como as rotas de navegação para o transporte e escoamento de matérias primas e produção econômica. Os mapas encontrados até o presente momento representam atividades e divisões administrativas que perpassam pelo século XVI e XVIII.

Quadro 1

Localização da APA do Pratigi, mapa da Bahia a esquerda. Elaboração: CUNHA, 2013.

\begin{tabular}{|l|l|l|l|}
\hline Satélite & Cenas & Ano & Banco de Dados \\
\hline LandSat 7 & $216 \_69$ e 216_70 & 2000 & Earth Explorer \\
\hline LandSat 5 & $216 \_69$ e 216_70 & 1994 & INPE \\
\hline LandSat 5 & $216 \_69$ e 216_70 & 1991 & INPE \\
\hline
\end{tabular}

\section{Resultados e Discussões}

No sistema nacional de unidades de conservação (SNUC-BRASIL), uma APA é definida como uma área extensa, apresentando ocupação humana, e constituída por elementos abióticos, bióticos, estéticos ou culturais. Tem como objetivo básico proteger a diversidade biológica e conduzir o processo de ocupação, promovendo o uso sustentável de parcela dos seus recursos presentes na região. (Sistema Nacional de Unidades de Conservação, 2000).

O Baixo Sul do Estado da Bahia historicamente não desenvolveu uma política industrial significativa. Com isso algumas culturas agrícolas estabelecidas na região se tornam responsáveis por impulsionar a economia local, e até a atualidade influenciam na organização do espaço. 0 mapeamento da dinâmica das atividades econômicas locais, assumem, portan- to, grande importância para o entendimento do processo de uso e ocupação das terras.

A tradição do policultivo na área de estudo pode explicar a preferência pela pratica da agricultura de consorcio. Tal pratica promove a manutenção de uma fisionomia de floresta para as áreas onde ela é implantada, muito embora a composição de espécies se afaste da estrutura original de uma floresta ombrófila. Isso é evidenciado pela reflectância presente na construção dos mapas e suas diferentes classes nas imagens de satélite. A classe de consorcio, apresenta uma coloração mais clara que permite tanto a diferenciação entre esta e a classe floresta, quando evidencia a sua composição mais raleada.

A resolução espacial das imagens LandSat não permitiu um aprofundamento na diferenciação entre os diferentes tipos de atividades destacadas e investigadas, e por isso optou-se pelas classes genéricas de "Consorcio" e "Cultivos Convencionais". A classe Consorcio corresponde ao plantio consorciado de espécies de estrativação vegetal arbóreas com finalidade comercial empreendidos na região, e que puderam ser verificadas em campo, quais sejam: consórcios entre cacau e seringueira; e entre cacau e banana da terra.

$\mathrm{Na}$ extensão do sitio de Ituberá, observa-se uma notável expansão do consórcio na porção leste e na mancha de floresta ombrófila densa. Além de um aumento significativo da vegetação de restinga na região litorânea, ampliando assim a supressão da sua cobertura vegetal (floresta ombrófila e vegetação rala de restinga), deixando exposto o solo arenoso da restinga.

Destaca-se, a presença e evolução dos fragmentos de consórcio dentro da mancha de floresta ombrófila nessa área, sugere-se que esta mata esteja manejada, pela introdução de espécies em sistema de consórcio.

\section{Considerações Finais}

As imagens trabalhadas no presente estudo permitiu a analise de dados e construção de mapas até os anos 2000 que correspondem a um período de apenas dois anos após a criação da APA do Pratigi. Desta forma, a avaliação do efeito da criação da APA sobre as modificações da paisagem e conservação dos recursos naturais ficou limitada. Entretanto, as analises permitiram identificar as atividades com maior potencial modificador da paisagem (consorcio agrícola), assim como as áreas mais ameaçadas (floresta ombrófila) na área de estudo. Esta pesquisa representa, portanto, uma contribuição importante para os processos de gestão da APA, no sentido de adequar as estratégias de conservação da natureza aos padrões de uso e ocupação da terra localmente.

Observou-se também que a dinâmica econômica parece ser a chave para a definição das formas de uso e ocupação da terra, já que os consórcios agrícolas empreendidos na área apresentam finalidade comercial, e não de recuperação da mata nativa. 

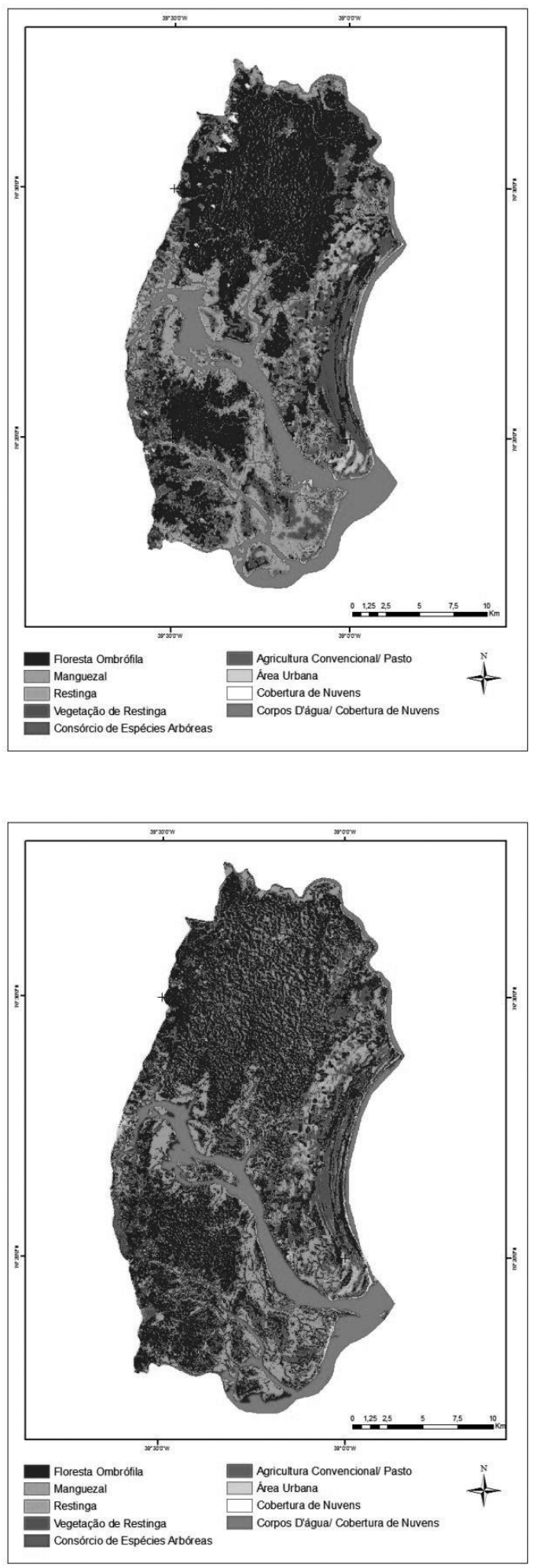

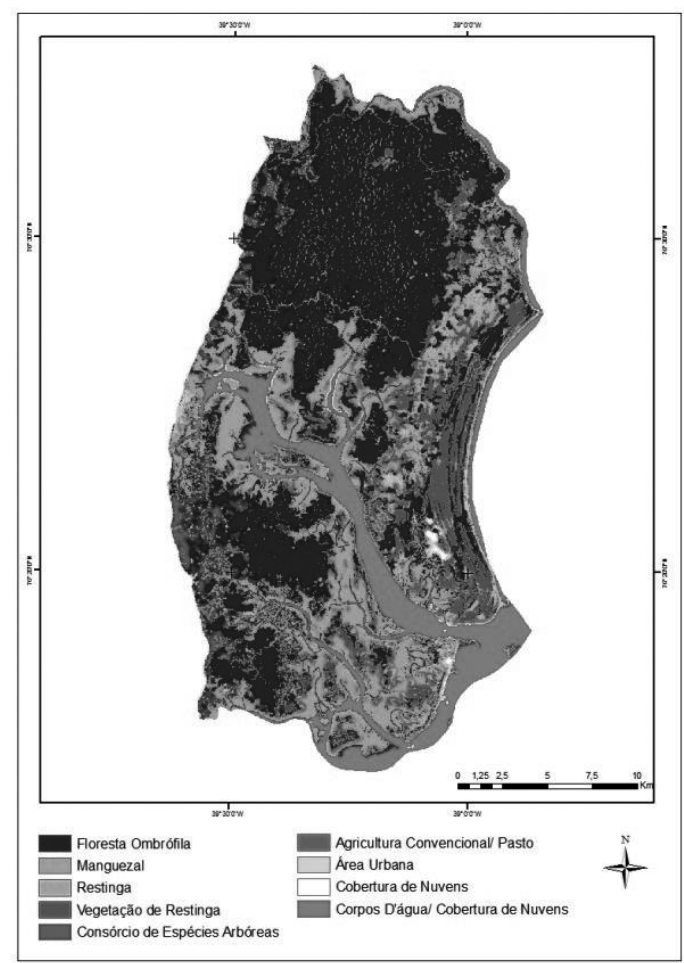

Figura 2

Sítio de Ituberá- BAHIA. BRASIL

Elaboração: Cunha,2013.

\section{Bibliografia:}

ADAN, C. F. F; CARTOGRAFIA DE UM ENGANO: NAVEGABILIDADE E INTEGRaÇão terRItorial na BaHIA COlonial. $1^{\circ}$ Simposio Brasileiro de Cartografia Historica. Paraty 2011.

Florenzano, Tereza Gallotti. Sensoriamento Remoto para Geomorfologia. In. Florenzano, Tereza Gallotti (org). Geomorfologia: conceitos e tecnologias atuais. São Paulo: Oficina de Textos, 2008.

freitas, Inês Aguiar de. História Ambiental e Geografia, anals no XX Encontro Nacional de Geógrafos, João Pessoa, 2002.A

fREITAS, Inês Aguiar de. História Ambiental e Geografia na obra de Alberto Lamego, Anals no XX Encontro Nacional de Geógrafos, JOÃO PESSOA, 2002. B

Freitas, Inês Aguiar de. A Geografia na construção de uma História Ambiental brasileira. Boletim Goiano de Geografia, Vol.22, N. 2, JUL/DEZ 2002.C. P. 155-168.

MARTINELLI, M. Cartografia ambiental: QUE CARTOgrafia É ESSA? In: souza, M. A. A. De; et all (orgs.). O novo mapa do MUNDO - NATUREzA E SOCIEDAdE dE hOJE: umA LEITURA Geográfica. São paulo: editora hucitec - ANPUR, 1993, v. 1, P. $232-242$. 
MINISTÉRIO do MEIO AMBIENTE. 2000. AvaliaÇão e aÇões PRIORITÁRIAS PARA A CONSERVAÇÃO DA BIODIVERSIDADE DA MATA AtLÂNTICA. Brasília.

OlmoS, Fábio. Espécies e Ecossitemas. São Paulo: Blucher, 2010.

passos, Messias Modesto. a Construção da Paisagem no Mato Grosso - Brasil. Maringá: Editora da UEM, 2000.

RoChA, R.B. et.al. Caracterização Sócio-Ambiental da Área de Proteção AMBIENTAL do PRATIGI. UESC/IFV/OCT. 2010. 39 P.
SILVA, ARdemírio de BarRos. Sistemas de INFORMAÇÕES GEO-REFERENCIADAS: conceitos e fundamentos. São Paulo, SP: Universidade de CAMPINAS, 1999.

SUERTEGARAY, Dirce Maria Antunes. Espaço Geográfico uno e múltiplo. SCRIPTA Nova. N. 93, 15 de JULIO de 2001.

WORSter, Donald. Para fazer História Ambiental. Estudos Históricos. Rio de Janeiro, Vol.4, N.8,1991, P.198-215. 